Forthcoming in Journal of Sex Research

http://dx.doi.org/10.1080/00224499.2017.1278736

\title{
Unbuckling the Bible Belt: A State-level Analysis of Religious Factors and Google Searches for Porn
}

\begin{abstract}
While the link between individual religious characteristics and pornography consumption is well established, relatively little research has considered how the wider religious context may influence pornography use. Exceptions in the literature to date have relied on relatively broad, subjective measures of religious commitment, largely ignoring issues of religious belonging, belief, or practice. This study moves the conversation forward by examining how a variety of state-level religious factors predict Google searches for the term "porn," net of relevant sociodemographic and ideological controls. Our multivariate findings indicate that higher percentages of evangelical Protestants, theists, and Biblical literalists in a state predict higher frequencies of searching for "porn," as do higher church attendance rates. Conversely, higher percentages of religiously unaffiliated persons in a state predict lower frequencies of searching for "porn." Higher percentages of total religious adherents, Catholics, or Mainline Protestants in a state are unrelated to searching for "porn" with controls in place. Contrary to recent research, our analyses also show that higher percentages of political conservatives in a state predicted lower frequencies of "porn" searches. Our findings support theories that more salient, traditional religious influences in a state may influence residents - whether religious or not - toward more covert sexual experiences.
\end{abstract}

Key words: pornography, religion, evangelicals, state-level data, political conservatism

Andrew L. Whitehead

Assistant Professor

Clemson University

Alw6@clemson.edu

Samuel L. Perry

Assistant Professor

University of Oklahoma

samperry@ou.edu 


\section{INTRODUCTION}

Religious beliefs, practices, and communities have always been important factors to consider in studies of pornography ${ }^{1}$ consumption (Davis \& Braucht, 1976; Grubbs, Exine, Pargament, Hook, \& Carlisle, 2015; Perry, 2016a; Perry \& Hayward 2017; Wilson \& Abelson, 1973). Religions typically teach that the only morally appropriate place for sexual desires and behavior is monogamous, married, heterosexual relationships. Consequently, religious groups, and most prominently conservative Protestants in the American context, strongly discourage any type of pornography, viewing it as a form of fornication that rouses and facilitates sexual desires about persons outside of marriage and encourages solo-masturbation (Driscoll, 2009; Sherkat \& Ellison, 1997). It is unsurprising, then, that studies of religion's relationship to porn viewing among American adults consistently find that those who report greater religious commitment (measured in a variety of ways) or who hold theologically conservative identities and beliefs are more likely to report either not viewing pornography at all (Doran \& Price, 2014; Grubbs et al., 2015; Maddox, Rhoades, \& Markman, 2011; Nelson, Padilla-Walker, \& Carroll, 2010; Patterson \& Price, 2012; Perry, 2016b; Stack, Wasserman, \& Kern., 2004; Wright, 2013; Wright, Bae, \& Funk, 2013) or doing so less frequently than others (Baltazar, Helm, McBride, Hopkins, \& Stevens, 2010; Bridges \& Morokoff, 2011; Carroll, Padilla-Walker, Nelson, Olson, Barry, \& Madsen, 2008; Hardy, Steelman, Coyne, \& Ridge, 2013; Perry, 2016c; Poulsen, Busby, \& Galovan, 2013; Short, Kasper, \& Wetterneck, 2015).

Yet while the connection between religious factors and porn consumption is wellestablished at the individual level, relatively few studies have considered how the broader

\footnotetext{
${ }^{1}$ The term "pornography" is difficult to define and is often replaced by other more descriptive terms like "sexually explicit media/material." However, the term pornography is still widely used, and because our study deals with the Google search term "porn," we use "pornography" or "porn" here. Throughout the study, pornography/porn will refer to any sexually explicit media (videos, websites, magazines, etc.) intended to arouse the viewer.
} 
religious context relates to pornography use. Among the exceptions, Edelman (2009) analyzed state-level covariates of credit card subscriptions to a leading adult entertainment website from 2006-2008. He found that subscriptions were more prevalent in states where surveys indicate more conservative stances on religion, sexuality, and gender roles. In their state-level analysis of pornography and divorce across time, Daines and Shumway (2011) found that Playboy magazine sales were strongly predictive of divorce rates, which are known to be higher in states with higher percentages of conservative Protestants (Glass \& Levchak, 2014). More recently, MacInnis and Hodson (2015) found positive associations between aggregated state-level selfidentified religiosity and political conservativism and searching for sexual content online. The authors aggregate individual-level responses to Gallup surveys of Americans to create state-level measures. In order to operationalize the religious context of each state they create a state religiosity index consisting of the percentage of respondents that (a) identify as "very religious" and (b) consider religion an important part of their daily lives. While this religiosity index is predictive in three of the fourteen multivariate models that control for other factors, it raises several important questions that require additional investigation. Namely, what is the character of that religiosity? Are particular religious groups more dominant in different areas? Which religious beliefs dominate? Are the communities active religiously?

While self-identified religiosity and importance of religion give us some insight into whether a community is religious, it tells us little about the nature of that religiosity. Two communities could appear equally religious when aggregating individual self-reports of religiosity, but at the same time exhibit divergent religious service attendance rates or different views of how the Bible should be interpreted. This could lead those same communities to having very different views toward various moral issues, like porn, for instance. Consistently, studies 
find that the religious groups with which individuals affiliate, their religious beliefs, and their religious behaviors routinely influence their views toward porn (Carroll et al., 2008; Lykke \& Cohen, 2015; Patterson \& Price, 2012; Sherkat \& Ellison, 1997) and various other moral issues (Hoffman, Ellison, \& Bartkowski, 2016; Perry, 2015; Whitehead \& Perry, 2016). Therefore, it is important to examine the content and character of religiosity at the state-level, rather than only examining aggregated measures of how religious individuals perceive themselves to be.

To do so, we draw on the theoretical tradition of moral communities. The concept of "moral communities" can be first attributed to Durkheim (1912/1995). In his various works he showed how high degrees of consensus concerning community norms, as well as the religious legitimation of those norms, significantly influence how those collectivities operate and the actions members might take due to their context (Durkheim, 1897/1951). A number of researchers draw on the concept of moral communities in their study of how human behavior is shaped by their surrounding social environment (Baker, Smith, \& Stoss, 2015; Gault-Sherman \& Draper, 2012; Hill, 2009; Lee \& Barkowski, 2004; Stark, 1996; Ulmer, Bader, \& Gault, 2008). Instead of seeing religion only as an individual-level trait, this literature demonstrates that religion is also a group property and a part of the social structure (Stark, 1996, p. 164). There is evidence that the religious context—measured through religious affiliation, belief, or behaviorof an area or state is significantly associated with a host of outcomes. The degree to which an area contains a greater proportion of particular religious traditions can influence cohabitation rates (Gault-Sherman \& Draper, 2012), crime (Beyerlein \& Hipp, 2005), gender attitudes (Moore \& Vanneman, 2003), same-sex policy outcomes (Scheitle \& Hahn, 2011), and population health (Blanchard et al., 2008). Strayhorn and Strayhorn (2009) find that teen birth rates are higher in states where a larger percentage of residents report higher religiosity and more conservative 
theological beliefs. And Baker and colleagues (2015) find that the percent of the population that hold various religious beliefs or attend religious services frequently can predict a state's posture toward sex education.

MacInnis and Hodson (2015) draw on the preoccupation hypothesis to explain the correlation between greater religiosity and political conservatism in a state and searches for sexrelated material. They theorize that religious persons and conservatives, perhaps due to underlying personality factors like authoritarianism, may become preoccupied with the very sexual content they oppose and thus pursue it covertly. While this explanation is certainly plausible and may be true, it is not falsifiable using aggregate state-level data, as MacInnis and Hodson (2015) point out. Indeed, it risks the ecological inference fallacy, in which inferences about individuals are incorrectly drawn from observations of aggregate groups (Kingston \& Malamuth, 2011; Robinson, 1950; Schuessler, 1999). As an alternative, we propose that the theoretical tradition of moral communities is more appropriate for understanding an analysis of state-level data. An important strength of the moral communities framework is that it is less susceptible to the ecological inference fallacy. The moral communities view posits that religion itself is a group-level phenomenon, and thus, the theoretical link between group-level religious characteristics and individual behavior does not require presumptions about the thought processes or personalities of individual actors, as with the preoccupation hypothesis. Our claims are not about which individual-level behaviors produce a particular group-level outcome, rather, that religious contexts - moral communities - can explain some of the variation in aggregated individual-level behaviors.

An additional strength of drawing on the moral communities thesis to understand the religion-pornography connection at the aggregate level is that it does not necessarily negate 
individual-level explanations - like the preoccupation hypothesis—utilized in prior literature (MacInnis \& Hodson, 2015). In fact, it allows that there may be a number of "different possible relationships at the individual level [that] can generate the same observation at the aggregate level" (Schuessler 1999, p. 10,578). Rather the moral communities thesis predicts significant effects of population-level variation in religious beliefs, behaviors, and affiliations.

Therefore, in order to further contextualize and expand upon prior macro-level analyses of religion and consumption of pornography, we hypothesize that the adherence rates to particular religious traditions, the percent of the population that hold traditional religious beliefs, and the average frequency with which people attend religious services will be significantly associated with the consumption of porn at the state level. Broadly, we propose that the religious nature of the social context surrounding people makes the consumption of online pornography either more or less acceptable. These measures will serve as more precise indicators of the moral communities in which people are embedded.

Beyond predicting that aggregate levels of religious affiliation, belief, and behavior are significantly associated with the popularity of searching for pornography at the state level, we propose two interpretations concerning the directionality of that association. In essence, religious moral communities could serve to either encourage or suppress searching online for sexual content. Each of these predictions draws upon prior research on religion and the consumption of pornography. We freely acknowledge that we cannot establish the individual-level activity that produces either of these interpretations. We can only demonstrate that a positive or negative association exists. First, religion, as we operationalize it below with state-level measures, may serve to suppress searching for sexual content online. A host of studies at the individual level demonstrate that religious individuals — especially conservative Protestants, theists, those who 
interpret the Bible literally, and those who attend religious services frequently—report lower levels of porn consumption (Carroll et al., 2008; Perry, 2016b, 2016c; Stack et al., 2004; Wright, 2013; Wright et al., 2013). We would expect, then, that states with higher proportions of religious individuals, who report lower consumption of porn, will have lower levels of porn consumption as a whole.

Alternatively, MacInnis and Hodson (2015) found that the popularity of searching for sexual content online was higher in states with higher proportions of people who identify as "religious" or say religion is very important to them. Using more precise measures of religion, we could find that the popularity of searching for sexual content online is higher in states with greater proportions of citizens with particular religious affiliations, beliefs, and behaviors. This could be due to two reasons. First, it may be that when asked directly religious individuals tend to underreport their consumption of explicit material given the labeling of such content as "sinful." This explanation rests on the assumption that the responses of religious individuals on anonymous surveys are strongly influenced by social desirability bias. Therefore, a strength of examining aggregate levels of porn consumption and the religiosity of varying contexts is that while certain religious markers may exhibit a relationship with porn consumption in one direction at the individual level—largely due to measurement error stemming from social desirability bias - at the group level the relationship could be completely opposite. In this sense, the anonymized aggregate data could be picking up actual behaviors rather than self-reported ones.

A second reason that searching for sexual content online could be more popular in more religious states is that it may not be religious individuals accessing sexual content online more frequently, but all citizens. The strong community-level norms and moral communities cultivated 
within more religious populations may make online searches for pornography more prevalent because there are few other outlets for sexual expression. Prior work on religious context and divorce rates demonstrates how religious moral communities can influence the non-religious, as well as the religious. Glass and Levchak (2014), for example, found that counties with higher percentages of conservative Protestants predicted higher divorce rates regardless of one's personal religious identification. They reasoned that the broader religious culture contributed to earlier ages at first marriage and lower collective educational attainment, strong predictors of divorce. Therefore, even for non-religious people, being surrounded by a social environment that is highly religious may make more intimate and private forms of sexuality ideal.

\section{METHOD}

In order to examine the state-level correlates of the popularity of Google searches for pornography, we draw from a number of diverse and publically available sources.

\section{Data and Measures}

\section{Outcome Variable}

The dependent variable represents the popularity of "porn" as a Google web search term for each of the 50 states from the period ranging from January 1, 2011 to July 31, 2016. ${ }^{2}$ Google Trends freely provides these data, and Google itself is the ideal search engine for this type of analysis given that it fulfills two-thirds of all internet searches. Certainly, "porn" is not the only Google search term that is used to access explicit material. Prior research (MacInnis \& Hodson 2015) examined a number of different terms. We limit our analysis to "porn" alone for several reasons. First, when tracking the popularity of the search terms "porn", "lesbian porn", "sex",

\footnotetext{
${ }^{2}$ We begin the search period at 1/1/2011 because on this date Google applied an improved algorithm for their geographical assignment. We include the subsequent five and a half years in order to smooth the random variation between years. In ancillary analyses, available upon request, we conducted analyses on each individual year included in this range. Those findings do not differ in significant or substantive ways from those described below.
} 
“sex tape", "xxx", "amateur porn", and "free porn", "porn" is far and away the most popular term entered into Google to access explicit material. Over the entire period that we analyze, “porn" accounts for almost twice as many searches as the second most searched term ("sex"), and accounts for more searches than all of the terms mentioned above, combined. Second, most likely due to its greater popularity, "porn" as a Google search term has a great deal of variation across the 50 states while the less popular terms ("sex" and "xxx") do not. For these other terms, the distribution is highly skewed with one state (Oregon) serving as an extreme outlier with most other states bunched together with much lower search scores. Subsequently, when we performed multivariate analyses on these terms very few variables were significantly associated in any of the models. We believe this is primarily due to a lack of variation to be explained. However, when we examined the terms "sex tape", "lesbian porn", "amateur porn", and "free porn" we found that their distributions as well as their bivariate and multivariate results were substantively identical to "porn" where the religion measures were consistently and significantly associated with the dependent variable in the same direction (results available upon request). Third, we believe an added benefit of concentrating on one particular term, and in this case by far the most popular, allows for a more focused and parsimonious analysis.

Google Trends calculates values for the popularity of a specified search term for each state on a scale from 0 to 100 over the specified time frame. The state assigned 100 is where the fraction of the total searches for the specified search term is the largest. The scores for all other states are computed in relation to the highest scoring state. A score of 50 is a state where the fraction of the total searches for the specified search term is half as large as the state with the highest proportion of searches. The strength of using Google trends is that it normalizes the popularity of a search term across states. Because it is a proportion of all searches, more 
populous states that generate higher volumes of total searches are placed on equal footing with

less populous states generating lower volumes of total searches. As prior research demonstrates,

Google Trends is an effective means through which public interest can be examined (MacInnis \&

Hodson, 2015; Scheitle, 2011). ${ }^{3}$

Independent Variables

In order to account for the relative sizes of various religious groups in each state, we draw on publically available data collected by the Association of Statisticians of American Religious Bodies (ASARB) made freely available at the Association of Religion Data Archives (www.theARDA.com). Since 1990, ASARB has collected data every ten years on the religious groups operating in the United States. In this study, we use data from the 2010 Religious Congregations and Membership Study (RCMS). The 2010 RCMS provides information on 236 religious groups and the number of congregations and adherents within each state and county in the United States. Using population totals, adherence rates for each religious group in each state are estimated.

Drawing on this data we estimate the total religious adherence rates for each state as well as three broad categorizations of Christian religious traditions. These are Evangelical Protestant, Mainline Protestant, and Catholic. Each state-level religious adherence measure shows the number of adherents per 1,000 population. ${ }^{4}$

\footnotetext{
${ }^{3}$ Unfortunately, Google Trends does not track information on whether terms were searched for using a computer, smartphone, tablet, or some other electronic device. Knowing this information might provide some insight into the demographics of the communities in which terms are being searched and how they consume porn.

${ }^{4}$ In other studies examining the contextual effects of religious groups at the macro level (Gualt-Sherman \& Draper, 2012; Ulmer et al., 2008) researchers utilize a Christian homogeneity/heterogeneity measure calculated from the adherence rates of three Christian groups: Evangelical Protestants, Mainline Protestants, and Catholics. The index varies between 0 and 1 where high scores equal more heterogamous populations in regards to these groups and low equals more homogenous populations $\left[\mathrm{H}=1\right.$ - $\left([\text { Evangelical adherence rate/total adherence rate }]^{2}+[\right.$ Mainline adherence rate/total adherence rate $]^{2}+\left[\right.$ Catholic adherence rate/total adherence rate $\left.\left.{ }^{2}\right)\right]$. In ancillary analyses, available upon request, we calculated the $\mathrm{H}$ index. It was not significantly associated with the state-level popularity of online searches for "porn" in either bivariate or multivariate analyses.
} 
The final group are those who identify as no religious affiliation. This data is from the 2007 U.S. Religious Landscape Survey collected by the Pew Forum on Religion and Public Life and is also made freely available on the ARDA. The 2007 U.S. Religious Landscape Survey is a nationally representative sample of 35,556 adults in United States households. For each state we create a percentage of the total respondents who identify with no particular religious affiliation.

In order to investigate the influence of religious beliefs and behaviors at the population level, we estimate the percent of each state that believes in God, the percent that identify as a biblical literalist, and a mean frequency of attendance measure for each state. Each of these statelevel measures are drawn from the 2007 U.S. Religious Landscape Survey discussed above.

\section{Control Variables}

We include a battery of control variables in the multivariate analyses. In individual analyses on porn consumption, political ideology, income, education, age, and marital status are all important variables (Perry, 2016b, 2016c; Stack et al., 2004; Wright, 2013; Wright et al., 2013). Using the 2007 U.S. Religious Landscape Survey and American Community Studies’ estimates from 2008-2012, we include measures of political ideology, income, education, age, and percent married of each state population. First, we control for the political context of each state with the percent of the population who identify as politically "conservative" or "very conservative". Regarding income, we use median household income for each state. To measure education we include the percent of each state population that is over age 25 and has a Bachelor's degree. We use the median age of each state and the percent married as the final control variables. Each of the estimates drawn from the 2007 U.S. Religious Landscape Survey and American Community Study are freely available from the ARDA. ${ }^{5}$

\footnotetext{
${ }^{5}$ In addition to the control variables that appear in the final models, we also examined a host of other state-level measures in both bivariate and multivariate models. These alternative measures included: percent voting for Obama
} 


\section{Statistical Analysis}

We first present descriptive statistics for the dependent variable, the independent variables, and control variables. Also in Table 1, we provide the correlations between the statelevel popularity of Google web searches for "porn" and the independent variables of interest and control variables. Next, in Figure 1 we display an array of bivariate scatter plots for those independent variables of interest that are significantly correlated with the dependent variable. We include linear trend lines, correlation coefficients, and levels of significance within each bivariate scatter plot. In Tables 2 and 3, we employ Ordinary Least Squares (OLS) multivariate regression to uncover whether the strong bivariate correlations between the various religion measures and web searches for "porn" are robust. We estimate eight separate models for Total Religious Adherence Rate, Evangelical Protestant Adherence Rate, Mainline Protestant Adherence Rate, Catholic Adherence Rate, Percent Identifying as No Affiliation, Percent Theist, Percent Biblical Literalist, and Mean Religious Service Attendance. Separate models are necessary because statelevel adherence rates across various religion measures are unavoidably collinear. ${ }^{6}$ We also display standardized coefficients in order to evaluate substantive significance instead of only statistical significance. We performed a series of robustness checks to ensure all OLS regression models were producing valid results and satisfied assumptions regarding error terms. Across all models in Table 2 and 3, the error residuals are normally distributed, their mean is equal to zero, and they are not correlated with any of the independent variables.

\section{RESULTS}

in 2012, percent voting for Obama in 2008, state income inequality, men's median age at marriage, women's median age at marriage, percent male, percent female, percent male population under 18, percent male population 18-34, percent male population 35-64, percent male population $65+$, percent of population under 18 , percent of population 18-34, percent of population 35-64, percent of population 65+, median male age, median female age, and percent white. Bivariate results are available upon request.

${ }^{6}$ Across all 8 models, no VIF scores exceed 3.48 with only 11 VIF scores (out of 48 total) exceeding 3. 
In Table 1 we find that all 50 states range from a score of 60 to 100 on the popularity of Google searches for "porn”. The mean score on this measure is 78.84. For perspective, a score of 50 represents half the proportion of searches for "porn" compared to the score of 100 . The mean total religious adherence rate in the US is almost 500 people per 1,000 population. The mean Evangelical Protestant adherence rate is 160 people. Mainline Protestants are slightly less populous with a mean adherence rate of 86 . The mean Catholic adherence rate is 169. Finally, across all 50 states about 13 percent of people identify as no particular religious affiliation. Over nine in 10 Americans are theists, half interpret the Bible literally, and over one-third identify as politically conservative. The average frequency of religious service attendance is close to once or twice a month for many Americans.

\section{[Table 1 about here]}

Table 1 also displays the correlations between each of the independent variables of interest and the popularity of "porn" as a Google search term. We can see that there is not a significant correlation between the proportion of web searches for "porn" and the total religious adherence rate for each of the 50 states. Similar to the total religious adherence rate, there appears to be no underlying relationship between the Mainline Protestant adherence rate for a state and the popularity of "porn" as a Google search term.

[Figure 1 about here]

The scatter plots contained in Figure 1 tell a very different story for the other independent variables of interest. Graphing the bivariate relationship between the popularity of Google searches for "porn" and Evangelical Protestant adherence rates for each state clearly demonstrates a strong, positive, and statistically significant correlation $(r=0.649 ; p<0.001)$. In states with a larger proportion of Evangelical Protestants, the popularity of searching for "porn" 
on Google is significantly higher. In contrast to Evangelical Protestant adherence rates, higher levels of Catholic adherence rates are significantly and negatively correlated $(\mathrm{r}=-0.354 ; \mathrm{p}<0.05)$ with popularity of Google searches for “porn”. In states with larger populations that do not affiliate with a religion the proportion of that state's total Google searches being for "porn" is lower. This relationship is both significant and negative $(r=-0.355 ; \mathrm{p}<0.05)$.

Turning from the religious affiliation measures to the religious belief and behavior measures, Figure 1 also contains a scatter plot of the percent of the state population that is theist and the popularity of "porn" as a search term. There is a moderately-strong, positive, and significant correlation $(r=0.592 ; \mathrm{p}<0.001)$ such that in states where more people believe in God the popularity of Google searches for "porn" is higher. Similarly, there is a strong, positive, and significant association between the popularity of "porn" as a search term and the percent of the population that identifies as a biblical literalist $(r=0.652 ; \mathrm{p}<0.001)$. Likewise, the last scatter plot in the array indicates a positive and significant association between the mean level of religious service attendance state-wide and Google searches for "porn" $(r=0.521 ; p<0.001)$. In states with more theists, biblical literalists, or a population who attends religious services more frequently the popularity of searching for "porn" on Google is significantly higher.

With six clear significant associations across the religious affiliation, belief, and behavior measures, we turn to multivariate modeling to assess whether these correlations are robust. Table 2 contains the results of the five OLS regression models for each religious tradition measure. Models 1 and 3 estimate the associations of total religious adherence rate and Mainline Protestant adherence rates alongside the various control variables. As with the bivariate analysis, total religious adherence and Mainline Protestant adherence are not significantly associated with state-level popularity of Google searches for "porn" in multivariate models. Median income, 
percent with a Bachelor's degree, and median age are all significantly and negatively associated with the popularity of searching for "porn" in these models, though.

[Table 2 about here]

Model 2 examines the effect of Evangelical Protestant adherence rates. Net of the control variables, Evangelical Protestant adherence rates are significantly and positively associated with searching for "porn" on Google $(\beta=0.36 ; p<0.05)$. In states with higher proportions of Evangelicals, searches for "porn" appear to be much more prevalent. Interestingly, although the percent of the population that identifies as politically conservative is positively correlated with Google searches for "porn" at the bivariate level $(\mathrm{r}=.315 ; \mathrm{p}<0.05)$, controlling for the proportion of Evangelicals and other sociodemographic controls, the association is now negative and nonsignificant. Higher median income $(\beta=-0.38 ; \mathrm{p}<0.05)$, median age $(\beta=-0.33 ; \mathrm{p}<0.01)$, percent married $(\beta=-0.24 ; \mathrm{p}<0.05)$ in the state are also negatively related to Google searches for "porn". Comparing the standardized coefficients, the Evangelical Protestant adherence rate is the second strongest measure in the model.

In contrast, however, Model 4 reveals that the Catholic adherence rate is not significantly associated with the popularity of "porn" as a Google search term net of the effects of the control variables. The significant bivariate correlation for the Catholic adherence rate measure appears to be due to other underlying factors. A state's median income, percent of the population with a Bachelor's degree, median age, and percent married are all significantly and negatively associated with the popularity of searching for "porn" on Google. Ancillary analyses, available upon request, demonstrate that Catholic adherence rate is significantly and strongly correlated with both median income and percent of the state population with a Bachelor's degree. It could be that the bivariate Catholic effect discussed above was actually due to differences in income 
and education within those states. In Model 5 we find that the percent of the population that does not affiliate with a religious tradition is significantly and negatively associated $(\beta=-0.26 ; p<0.05)$ with the popularity of searching for the term "porn" on Google, net of all other effects. In this model, political conservatism, income, education, age, and percent married are all significantly and negatively associated, as well. Substantively, however, percent unaffiliated is the secondweakest significant association in the model.

[Table 3 about here]

Table 3 contains the final three OLS regression models for the religious belief and behavior measures. In Model 1 we find, as with the bivariate correlation, that as the percent of the state population that is theist increases, the popularity of searching for "porn" on Google increases $(\beta=0.47 ; \mathrm{p}<0.01)$. Percent conservative, median income, median age, and percent married are all significantly and negatively associated. Substantively, percent theist has the largest standardized coefficient in the model. In Model 2 a similar story emerges where percent of the state that identifies as biblical literalist is significantly and positively associated with the popularity of searching for "porn" on Google $(\beta=0.36 ; \mathrm{p}<0.05)$. Median income, median age, and percent married are the other significant measures. Finally, in Model 3 we find that mean levels of the frequency of religious behavior is significantly and positively associated with Google searches for "porn" $(\beta=0.37 ; \mathrm{p}<0.05)$. Percent politically conservative, median income, median age, and percent married are each significantly and negatively associated. However, mean attendance has the second largest standardized coefficient, net of all other effects.

\section{DISCUSSION AND CONCLUSION}

Prior research established that aggregate levels of self-identified "religiosity" are linked with searching for porn on the internet (MacInnis \& Hodson, 2015). We build upon this work 
and provide a necessary expansion with increased precision regarding the characteristics and contours of aggregate religiosity and spirituality. Specifically, we examine how religious affiliation adherence rates for multiple groups, aggregated religious beliefs, and average levels of religious behavior are all linked to the popularity of searching for the term "porn" on Google. States with more individuals in the Evangelical Protestant tradition, a greater percentage of theists, a larger proportion of biblical literalists, or a higher mean level of religious service attendance are all linked to a higher proportion of searches for "porn" across all Google search engine queries. Conversely, in states with larger proportions of individuals who do not affiliate with a religious tradition, searching for "porn" on Google is less popular. Standardized regression coefficients also make clear that aggregate measures of religious belief, behavior, and affiliation are consistently among the covariates most strongly associated with the dependent variable. This highlights the importance of accounting for religious variation at the populationlevel when examining aggregate outcomes concerning behaviors or attitudes centered on perceived moral issues.

There are a number of possible explanations for the significant and positive association between higher proportions of Evangelical Protestants, theists, biblical literalists, and religious services attenders and online searches for "porn." While we openly acknowledge that we cannot definitively determine who is searching for this content, or under what circumstances, we can explore the possible options in light of our theoretical framework. Drawing on the moral communities thesis, we posit that higher adherence rates to the Evangelical Protestant tradition, more theists, more biblical literalists, or more people attending religious services creates a cultural context, a moral community, where more overt expressions of sexuality are generally treated with disdain (Baker et al., 2015; Gault-Sherman \& Draper, 2012; Hill, 2009; Lee \& 
Barkowski, 2004; Stark, 1996; Ulmer et al., 2008). In this tradition, human behavior is shaped by the surrounding social context and religion is a group-level trait and an important part of the social structure (Stark, 1996). These religious moral communities might privilege—or forcemore covert forms of sexual expression for those who belong to these groups and even among those who do not. In the midst of a strong moral community both the religious and the nonreligious may have limited opportunities for expressing certain aspects of their sexuality. Searching online for sexually explicit material, where access is anonymous and outside the purview of disapproving religious communities and people, may be a useful and necessary outlet.

A related explanation not explored in prior research could be that it is not religious adults searching for terms like "porn" on Google, but the youth in their homes and communities. Religiously devout and conservative parents tend to provide less sex education to their children, and they also tend to monitor their children's overt sexual activities more closely, either directly themselves or indirectly through their religious community (Regnerus, 2005, 2007). It could be that the youth in strongly religious moral communities are left with few options for sexual education or expression and thus are more likely to search for "porn" online. Related to this point, it is important to acknowledge that just because people are searching for "porn" does not necessarily mean that they are using it. While it is likely that most people who are surfing for pornographic content are planning to view it, some of this searching, especially if it is performed by younger people, may be out of sheer curiosity.

Even for those outside of these religious moral communities it may be that online pornography is their primary (or essentially only) outlet, though the non-religious may have the opportunity to explore various types of sexual expression in less religious contexts. Conversely, 
in states with greater percentages of unaffiliated individuals, searching for porn may be less necessary given their greater opportunity for interpersonal sexual exploration because the community-level norms and surveillance against it are not as prevalent. Furthermore, the youth in less religious homes and communities may receive more sex education through both formal (Baker et al., 2015) and informal channels making online searches non-essential. It is important to note that only through examining the actual content and character of aggregated religiosity would the above explanation be plausible. Because prior research highlights the actual beliefs and behaviors of people in particular religious groups — such as Evangelicals providing less sex education to their youth —we are then able to offer alternative justifications for the overall finding that more religious areas manifest more online searches for sexually explicit material.

However, it could also be that these groups-Evangelicals, theists, biblical literalists, and frequent church-goers - actually perform more searches for online porn because it is a secret and private form of sexual expression that they do not feel the ability to express due to group-level norms and restrictions on explicit sexuality. As the "breastplate of righteousness" concept and the preoccupation hypothesis would predict (MacInnis \& Hodson, 2015), these individuals outwardly disdain pornography but in their private moments consume it at relatively higher levels. There is no way to actually verify this possibility, unfortunately, since we do not have data on the religious affiliation, beliefs, or behaviors of individual Google searchers. A related possibility is that devout and conservative religious persons are more likely to binge on porn in compulsive cycles. Religious persons experience greater shame and guilt due to their porn use and are also more likely to consider themselves "addicted" to pornography compared to others (Abell et al., 2006; Grubbs et al. 2016; MacInnis \& Hodson 2016). It could be that the more negative self-evaluations stemming from their porn use lead religious persons into cycles of 
binging and abstention. But again, testing this possibility would require future studies to incorporate individual measures.

It is important to compare these findings to those that dominate the religion-porn connection using primarily individual level data. In that literature, religiosity is almost always associated with lower levels of porn consumption. Evangelical Protestants report the lowest levels of porn consumption with other measures of religiosity like biblical literalism and religious service attendance evincing similar relationships (see Perry, 2016c; Wright, 2013; Wright et al., 2013). Yet, these studies are overwhelmingly based upon self-reports which could be problematic given that consumption of pornography is especially stigmatized among conservative religious Americans. Since Google Trends is an anonymized and aggregate measure of this stigmatized activity it could be that we are able to circumvent possible measurement error due to social desirability bias allowing a less cultivated view of the levels to which individuals consume porn. However, the strength of using an anonymized measure of a stigmatized activity is also a weakness. We are not able to uncover who is doing the searching for "porn" on Google, only that it is much more likely to occur in places with more Evangelicals, theists, biblical literalists, or people who attend religious services often. Despite this limitation, future work should continue to examine aggregated measures of religiosity/moral communities in relation to morality issues, including but not limited to porn.

Additionally, it is important to point out that by comparing the present analysis to findings at the individual level it is clear that aggregate-level relationships need not be identical to individual-level associations (Kingston \& Malamuth, 2011; Robinson, 1950; Schuessler, 1999). Again, it is entirely possible that areas with more conservative Protestants, theists, biblical literalists, and frequent church attenders simultaneously have high rates of searches for 
explicit content online while those same individuals - conservative Protestants, theists, biblical literalists, and frequent church attenders — are not searching for sexually explicit content individually. Such is the power, and importance theoretically, of the concept of moral communities and recognizing religion as not only an individual-level trait but a vital part of the social structure. Prior research that used individual-level theories and explanations to explain aggregate-level relationships suffered from the ecological inference problem (Kingston \& Malamuth, 2011; Robinson, 1950; Schuessler, 1999). Above we posited several possible explanations for the religion-porn connection at the state-level. However, the focus of this study and the moral communities hypothesis is that contextual measures of religion should be significantly associated with aggregate behaviors in the population. In this case, the moral communities hypothesis and our use of aggregate measures highlights the somewhat counterintuitive relationship where religion is associated with more Google searches for "porn."

Our analyses also demonstrate that the percentage of each state who identify politically as "conservative" or "very conservative" is negatively related to the popularity of "porn" as a search term on Google. This suggests that it is not merely about any type of conservatism- be it religious or political_-but the broader religious climate in particular that is associated with higher overall levels of searching for "porn.” The moral communities established through particular religious affiliations, beliefs, and practices are related to these practices in a way that political conservatism is not. Put another way, it is the broader religious climate - not political conservatism - that is driving these practices into more private arenas and constricting more open expressions of sexuality. This line of thinking is also supported by the fact that the initial bivariate association between state-level political conservatism and "porn" searches is positive, but becomes negative when controlling for religious and other sociodemographic factors. 
Political conservatism in the aggregate may serve as a proxy for religious conservatism, but when isolated is in fact negatively related to searching for sexual content. These findings counter prior work in this area which finds no association between overall conservatism and searching for "porn" (MacInnis \& Hodson, 2015). In fact, MacInnis and Hodson (2015) find that political conservatism is positively related to Google image searches for "sex", but no other search terms. One reason why these findings differ could be that our more precise operationalization of religion and our broader collection of covariates produce a more specified model.

Overall, this analysis establishes that the religious context of a geographic area is significantly associated with aggregate levels of pornography use. Specifically, we show that the aggregated character and content of religion - religious belonging, beliefs, and practice-matter greatly when attempting to delineate its relationship to aggregate measures of private sexual activity. Communities may look equally religious, but divergent religious beliefs, religious service attendance rates, or greater adherence to different religious traditions has profound implications for the community at-large. This analysis illustrates the importance of accounting for those differences in order to better understand the possible mechanisms underlying these associations. As the moral communities theory literature makes clear, human behavior is shaped by the surrounding social environment and religion is a vital part of social structure. It is a group property, not just an individual-level trait. It is important for future research of online sexual behavior to continue to account for religion as an important and powerful social force. 


\section{REFERENCES}

Abell, J. W., Steenbergh, T. A., \& Boivin, M. J. (2006). Cyberporn use in the context of religiosity. Journal of Psychology and Theology, 34(2), 165-171.

Baker, J. O., Smith, K. K., Stoss, Y. A. (2015). Theism, secularism, and sexual education in the United States. Sexuality Research and Social Policy, 12(3), 236-247.

Baltazar, A., Helm, H.W., McBride, D., Hopkins, G., \& Stevens, J.V. (2010). Internet pornography use in the context of external and internal religiosity. Journal of Psychology and Theology, 38, 32-40.

Beyerlein, K., \& Hipp, J. R. (2005). Social capital, too much of a good thing? American religious traditions and community crime. Social Forces, 84(2), 995-1013.

Blanchard, T. C., Bartkowski, J. P.., Matthews, T. L., Kerley, K. R. (2008). Faith, morality, and mortality: The ecological impact of religion on population health. Social Forces, 86(4), 1591-1620.

Bridges, A. J., \& Morokoff, P. J. (2011). Sexual media use and relational satisfaction in heterosexual couples. Personal Relationships, 18, 562-585.

Carroll, J.S., Padilla-Walker, L.M., Nelson, L.J., Olson, C.D., McNamara Barry, C., \& Madsen, S.D. (2008). Generation XXX: Pornography acceptance and use among emerging adults. Journal of Adolescent Research, 23(1), 6-30.

Daines, R. M., \& Shumway, T. (2011). Pornography and divorce. $7^{\text {th }}$ Annual Conference on Empirical Legal Studies Paper. Available at SSRN: http://papers.ssrn.com/sol3/papers.cfm?abstract_id=2112435.

Davis, K. \& Braucht, G. (1976). Exposure to pornography, character, and sexual deviance: A retrospective survey. Journal of Social Issues, 29, 183-196. 
Doran, K., \& Price, J. (2014). Pornography and marriage. Journal of Family and Economic Issues, 35, 489-498.

Driscoll, M. (2009). Porn again Christian: A frank discussion on pornography and masturbation. Seattle, WA: Mars Hill Church.

Durkheim, E. (1951). Suicide: A study in sociology. New York: Free Press. (Original work published in 1897)

Durkheim, E. (1995). The elementary forms of the religious life. New York: The Free Press. (Original work published in 1912)

Edelman, B. (2009). Red light states: Who buys on-line adult entertainment? Journal of Economic Perspectives, 23, 209-220.

Gault-Sherman, M., \& Draper, M. (2012). What will the neighbors think? The effect of moral communities on cohabitation. Review of Religious Research, 54(1), 45-67.

Glass, J., \& Levchak, P. (2014). Red states, blue states, and divorce: Understanding the impact of conservative Protestantism on religion variation in divorce rates. American Journal of Sociology, 119(4), 1002-1046.

Grubbs, J.B., Exline, J.J., Pargament, K.I., Hook, J.N., \& Carlisle, R.D. (2015). Transgression as addiction: Religiosity and moral disapproval as predictors of perceived addiction to pornography. Archives of Sexual Behavior, 44(1), 125-136.

Hoffmann, J. P., Ellison, C. G., Bartkowski, J.P. (2016). Conservative Protestantism and attitudes toward corporal punishment, 1986-2010. Social Science Research (in press).

Kingston, D. A., \& Malamuth, N. M. (2011). Problems with aggregate data and the importance of individual differences in the study of pornography and sexual aggression: Comment on Diamond, Jozifkova, and Weiss. Archives of Sexual Behavior, 40(5), 1045-1048. 
Lee, M. R., Bartkowski, J. P. (2004). Love thy neighbor? Moral communities, civic engagement, and juvenile homicide in rural areas. Social Forces, 82(3), 1001-1035.

Lykke, L. C., \& Cohen, P. N. (2015). The widening gender gap in opposition to pornography, 1975-2012. Social Currents, 2(4), 307-323.

MacInnis, C. C., \& Hodson, G. (2015). Do American states with more religious or conservative populations search more for sexual content on Google? Archives of Sexual Behavior, 44, 137-147.

MacInnis, C. C., \& Hodson, G. (2016). Surfing for sexual sin: Relations between religiousness and viewing sexual content online. Sexual Addiction \& Compulsivity, 23, 196-210.

Moore, L. M., \& Vanneman, R. (2003). Context matters: Effects of the proportion of fundamentalists on gender attitudes. Social Forces, 82(1), 115-139.

Nelson, L.J., Padilla-Walker, L.M., \& Carroll, J.S. (2010). "I believe it is wrong but I still do it": A comparison of religious young men who do versus do not use pornography. Psychology of Religion and Spirituality, 2, 136-147.

Patterson, R., \& Price, J. (2012). Pornography, religion, and the happiness gap: Does pornography impact the actively religious differently? Journal for the Scientific Study of Religion, 51(1), 79-89.

Perry, S. L. (2015). Bible beliefs, conservative religious identity, and same-sex marriage support: Examining main and moderating effects. Journal for the Scientific Study of Religion, 54(4), 792-813.

Perry, S. L. (2016a). Does viewing pornography diminish religiosity over time? Evidence from longitudinal data. The Journal of Sex Research, doi: 10.1080/00224499.2016.1146203.

Perry, S. L. (2016b). Spousal religiosity, religious bonding, and pornography consumption. 
Archives of Sexual Behavior, doi: 10.1007/s10508-016-0896-y

Perry, S. L. (2016c). From bad to worse? Pornography consumption, spousal religiosity, gender, and marital quality. Sociological Forum, 31(2), 441-464.

Perry, S. L., \& Hayward, G. (2017). Seeing is (not) believing: How viewing pornography shapes the religious lives of young Americans. Social Forces, doi: 10.1093/sf/sow106.

Poulsen, F.O., Busby, D.M., \& Galovan, A.M. (2013). Pornography use: Who uses it and how it is associated with couple outcomes. Journal of Sex Research, 50(1), 72-83.

Price, J., Patterson, R., Regnerus, M., \& Walley, J. (2015). How much more XXX is Generation X consuming? Evidence of changing attitudes and behaviors related to pornography since 1973. Journal of Sex Research, doi: 10.1080/00224499.2014.1003773

Regnerus, M. D. (2005). Talking about sex: Religion and patterns of parent-child communication about sex and contraception. The Sociological Quarterly, 46, 79-105.

Regnerus, M. D. (2007). Forbidden fruit: Sex and religion in the lives of American teenagers. New York: Oxford University Press.

Robinson, W. S. (1950). Ecological correlations and the behavior of individuals. American Sociological Review, 15, 351-357.

Scheitle, C. P. (2011). Google insights for search: A note evaluating the use of search engine data in social research. Social Science Quarterly, 91(1), 285-295.

Scheitle, C. P., \& Hahn, B. B. (2011). From pews to policy: Specifying evangelical Protestantism's influence on states' sexual orientation policies. Social Forces, 89(3), 913933.

Sherkat, D., \& Ellison, C. (1997). The cognitive structure of a moral crusade: Conservative Protestantism and opposition to pornography. Social Forces, 75, 957-82. 
Stack, S., Wasserman, I., \& Kern, R. (2004). Adult social bonds and use of internet pornography. Social Science Quarterly, 85(1), 75-88.

Stark, R. (1996). Religion as context: Hellfire and delinquency one more time. Sociology of Religion, 57(2), 163-173.

Strayhorn, J. M., \& Strayhorn, J. C. (2009). Religiosity and teen birth rate in the United States. Reproductive Health, 6(14), doi: 10.1186/1742-4755-6-14.

Ulmer, J. T., Bader, C., Gault, M. (2008). Do moral communities play a role in criminal sentencing? Evidence from Pennsylvania. The Sociological Quarterly, 49(4), 737-768.

Whitehead, A. L., \& Perry, S. L. (2016). Religion and support for adoption by same-sex couples: The relative effects of religious tradition, practices, and beliefs. Journal of Family Issues, 37(6), 789-813.

Wilson, W., \& Abelson, H. (1973). Experiences with and attitudes toward explicit sexual materials. Journal of Social Issues, 29, 19-39.

Wright, P.J. (2013). U.S. males and pornography, 1973-2010: Consumption, predictors, and correlates. Journal of Sex Research, 50, 60-71.

Wright, P.J., Bae, S., \& Funk, M. (2013). United States women and pornography through four decades: Exposure, attitudes, behaviors, and individual differences. Archives of Sexual Behavior, 42, 1131-1144. 
Table 1: Descriptive Statistics

\begin{tabular}{|c|c|c|c|c|c|}
\hline & Mean & $\mathrm{SD}$ & Min & Max & $\begin{array}{l}\text { Google } \\
\text { Web Search }\end{array}$ \\
\hline Google Web Search "Porn" & 78.84 & 9.54 & 60 & 100 & --- \\
\hline $\begin{array}{l}\text { Total Religious Adherence } \\
\text { Rate }\end{array}$ & 483.39 & 103.35 & 276.31 & 791.06 & 0.099 \\
\hline $\begin{array}{l}\text { Evangelical Protestant } \\
\text { Adherence Rate }\end{array}$ & 160.13 & 108.67 & 22.81 & 420.41 & $0.649 * * *$ \\
\hline $\begin{array}{l}\text { Mainline Protestant } \\
\text { Adherence Rate }\end{array}$ & 86.13 & 56.72 & 8.52 & 292.66 & 0.014 \\
\hline Catholic Adherence Rate & 169.25 & 104.89 & 35.15 & 449.05 & $-0.354 *$ \\
\hline $\begin{array}{l}\text { Percent Identifying as No } \\
\text { Religion }\end{array}$ & 12.70 & 3.71 & 5.30 & 19.90 & $-0.355^{*}$ \\
\hline Percent Theist & 92.33 & 3.27 & 83.70 & 99.10 & $0.592 * * *$ \\
\hline Percent Biblical Literalist & 50.33 & 10.07 & 29.70 & 73.00 & $0.652 * * *$ \\
\hline Mean Attendance & 3.70 & 0.37 & 2.98 & 4.63 & $0.521 * * *$ \\
\hline Percent Conservative & 37.83 & 6.10 & 28.00 & 54.50 & $0.315^{*}$ \\
\hline Median Household Income & 53,104 & 8,672 & 38,882 & 72,999 & $-0.593 * *$ \\
\hline $\begin{array}{l}\text { Percent of Population with } \\
\text { BA }\end{array}$ & 17.65 & 2.72 & 11.01 & 23.45 & $-0.624 * * *$ \\
\hline Median Age of Population & 37.58 & 2.27 & 29.30 & 42.8 & $-0.255 \dagger$ \\
\hline Percent Married & 50.37 & 2.68 & 45.35 & 56.98 & $-0.272 \dagger$ \\
\hline
\end{tabular}

$\mathrm{N}=50 ; * * * \mathrm{p}<0.001 ; * * \mathrm{p}<0.01 ;{ }^{*} \mathrm{p}<0.05 ; \dagger \mathrm{p}<0.10$ 
Table 2: OLS Regression Analysis of State-Level Google Searches for "Porn" and Religious Adherence Rates

\begin{tabular}{|c|c|c|c|c|c|c|c|c|c|c|}
\hline & \multicolumn{2}{|c|}{$\begin{array}{l}\text { Total Religious } \\
\text { Adherence Rate }\end{array}$} & \multicolumn{2}{|c|}{$\begin{array}{l}\text { Evangelical Prot. } \\
\text { Adherence Rate }\end{array}$} & \multicolumn{2}{|c|}{$\begin{array}{l}\text { Mainline Prot. } \\
\text { Adherence Rate }\end{array}$} & \multicolumn{2}{|c|}{$\begin{array}{l}\text { Catholic Adherence } \\
\text { Rate }\end{array}$} & \multicolumn{2}{|c|}{$\begin{array}{l}\% \text { Identifying as } \\
\text { No Affiliation }\end{array}$} \\
\hline & $\mathrm{b}(\mathrm{SE})$ & $\beta$ & $\mathrm{b}(\mathrm{SE})$ & $\beta$ & $\mathrm{b}(\mathrm{SE})$ & $\beta$ & $\mathrm{b}(\mathrm{SE})$ & $\beta$ & $\mathrm{b}(\mathrm{SE})$ & $\beta$ \\
\hline $\begin{array}{l}\text { Total Religious } \\
\text { Adherence Rate }\end{array}$ & $\begin{array}{l}-0.01 \\
(0.01)\end{array}$ & -0.14 & --- & $\begin{array}{l}-- \\
\end{array}$ & --- & --- & --- & --- & --- & --- \\
\hline $\begin{array}{l}\text { Evangelical } \\
\text { Protestant }\end{array}$ & --- & --- & $\begin{array}{l}0.03 * \\
(0.01)\end{array}$ & 0.36 & --- & --- & --- & --- & --- & --- \\
\hline $\begin{array}{l}\text { Adherence Rate } \\
\text { Mainline Protestant } \\
\text { Adherence Rate }\end{array}$ & --- & --- & --- & --- & $\begin{array}{l}0.02 \\
(0.02)\end{array}$ & 0.15 & --- & --- & --- & --- \\
\hline $\begin{array}{l}\text { Catholic Adherence } \\
\text { Rate }\end{array}$ & --- & --- & --- & --- & --- & --- & $\begin{array}{l}-0.01 \\
(0.01)\end{array}$ & -0.11 & --- & --- \\
\hline $\begin{array}{l}\% \text { Identifying as No } \\
\text { Affiliation }\end{array}$ & --- & --- & --- & --- & --- & --- & --- & --- & $\begin{array}{l}-0.64 * \\
(0.32)\end{array}$ & -0.26 \\
\hline$\%$ Conservative & $\begin{array}{l}-0.03 \\
(0.25)\end{array}$ & 0.02 & $\begin{array}{l}-0.36 \\
(0.21)\end{array}$ & -0.23 & $\begin{array}{l}-0.27 \\
(0.22)\end{array}$ & -0.17 & $\begin{array}{l}-0.19 \\
(0.21)\end{array}$ & -0.12 & $\begin{array}{l}-0.48 \\
(0.26)\end{array}$ & -0.31 \\
\hline Median Income & $\begin{array}{l}-0.001 * * \\
(0.00)\end{array}$ & -0.49 & $\begin{array}{l}-0.0004^{*} \\
(0.00)\end{array}$ & -0.38 & $\begin{array}{l}-0.001 * * \\
(0.00)\end{array}$ & -0.48 & $\begin{array}{l}-0.001 * * \\
(0.00)\end{array}$ & -0.48 & $\begin{array}{l}-0.001 * * \\
(0.00)\end{array}$ & -0.49 \\
\hline$\%$ with BA Degree & $\begin{array}{l}-0.74 \\
(0.56)\end{array}$ & -0.21 & $\begin{array}{l}-0.54 \\
(0.53)\end{array}$ & -0.15 & $\begin{array}{l}-0.91 \\
(0.56)\end{array}$ & -0.26 & $\begin{array}{l}-0.67 * \\
(0.60)\end{array}$ & -0.19 & $\begin{array}{l}-0.91 \\
(0.54)\end{array}$ & -0.26 \\
\hline Median Age & $\begin{array}{l}-1.69^{* *} \\
(0.51)\end{array}$ & -0.40 & $\begin{array}{l}-1.41 * * \\
(0.47)\end{array}$ & -0.33 & $\begin{array}{l}-1.80 * * \\
(0.52)\end{array}$ & -0.43 & $\begin{array}{l}-1.49 * * \\
(0.50)\end{array}$ & -0.35 & $\begin{array}{l}-1.70 * * \\
(0.48)\end{array}$ & -0.40 \\
\hline Percent Married & $\begin{array}{l}-1.09 * * \\
(0.39)\end{array}$ & -0.31 & $\begin{array}{l}-0.86^{*} \\
(0.37)\end{array}$ & -0.24 & $\begin{array}{l}-1.15^{* *} \\
(0.40)\end{array}$ & -0.33 & $\begin{array}{l}-1.17 * \\
(0.44)\end{array}$ & -0.33 & $\begin{array}{l}-0.83^{*} \\
(0.38)\end{array}$ & -0.23 \\
\hline Intercept & $246.10 * * *$ & & $215.39 * * *$ & & $256.85 * * *$ & & $242.47 * * *$ & & $255.33 * * *$ & \\
\hline Adj. $R^{2}$ & 0.527 & & 0.583 & & 0.534 & & 0.522 & & 0.557 & \\
\hline $\mathrm{N}$ & 50 & & 50 & & 50 & & 50 & & 50 & \\
\hline
\end{tabular}

$* * * \mathrm{p}<0.001 ; * * \mathrm{p}<0.01 ; * \mathrm{p}<0.05$ 
Table 3: OLS Regression Analysis of State-Level Google Searches for "Porn" and Religious Belief and Attendance Rates

\begin{tabular}{|c|c|c|c|c|c|c|}
\hline & \multicolumn{2}{|c|}{ Percent Theist } & \multicolumn{2}{|c|}{ Percent Biblical Literalist } & \multicolumn{2}{|c|}{ Mean Attendance Rate } \\
\hline & $\mathrm{b}(\mathrm{SE})$ & $\beta$ & $\mathrm{b}(\mathrm{SE})$ & $\beta$ & $\mathrm{b}(\mathrm{SE})$ & $\beta$ \\
\hline Percent Theist & $\begin{array}{l}1.37 * * \\
(0.45)\end{array}$ & 0.47 & $\begin{array}{ll}-- \\
\end{array}$ & --- & --- & --- \\
\hline Percent Biblical Literalist & --- & --- & $\begin{array}{l}0.34^{*} \\
(0.14)\end{array}$ & 0.36 & --- & --- \\
\hline Mean Attendance Rate & --- & --- & --- & --- & $\begin{array}{l}9.46^{*} \\
(4.36)\end{array}$ & 0.37 \\
\hline$\%$ Conservative & $\begin{array}{l}-0.59 * \\
(0.24)\end{array}$ & -0.37 & $\begin{array}{l}-0.34 \\
(0.21)\end{array}$ & -0.22 & $\begin{array}{l}-0.57^{*} \\
(0.28)\end{array}$ & -0.37 \\
\hline Median Income & $\begin{array}{l}-0.0004 * \\
(0.00)\end{array}$ & -0.36 & $\begin{array}{l}-0.001 * * \\
(0.00)\end{array}$ & -0.46 & $\begin{array}{l}-0.001 * * \\
(0.00)\end{array}$ & -0.46 \\
\hline$\%$ with BA Degree & $\begin{array}{l}-0.65 \\
(0.52)\end{array}$ & -0.18 & $\begin{array}{l}-0.16 \\
(0.59)\end{array}$ & -0.05 & $\begin{array}{l}-0.65 \\
(0.54)\end{array}$ & -0.18 \\
\hline Median Age & $\begin{array}{l}-1.42^{* *} \\
(0.46)\end{array}$ & -0.34 & $\begin{array}{l}-1.55^{* *} \\
(0.47)\end{array}$ & -0.37 & $\begin{array}{l}-1.45^{* *} \\
(0.48)\end{array}$ & -0.34 \\
\hline Percent Married & $\begin{array}{l}-0.95^{*} \\
(0.36)\end{array}$ & -0.27 & $\begin{array}{l}-0.88 * \\
(0.37)\end{array}$ & -0.25 & $\begin{array}{l}-0.89 * \\
(0.38)\end{array}$ & -0.25 \\
\hline Intercept & $108.34 *$ & & $206.45 * * *$ & & $202.90 * * *$ & \\
\hline Adj. $R^{2}$ & 0.600 & & 0.577 & & 0.563 & \\
\hline $\mathrm{N}$ & 50 & & 50 & & 50 & \\
\hline
\end{tabular}

$* * * \mathrm{p}<0.001 ; * * \mathrm{p}<0.01 ; * \mathrm{p}<0.05$ 
Figure 1: Scatter Plots for Popularity of "Porn" as Google Search Term and Various Religion Measures by State
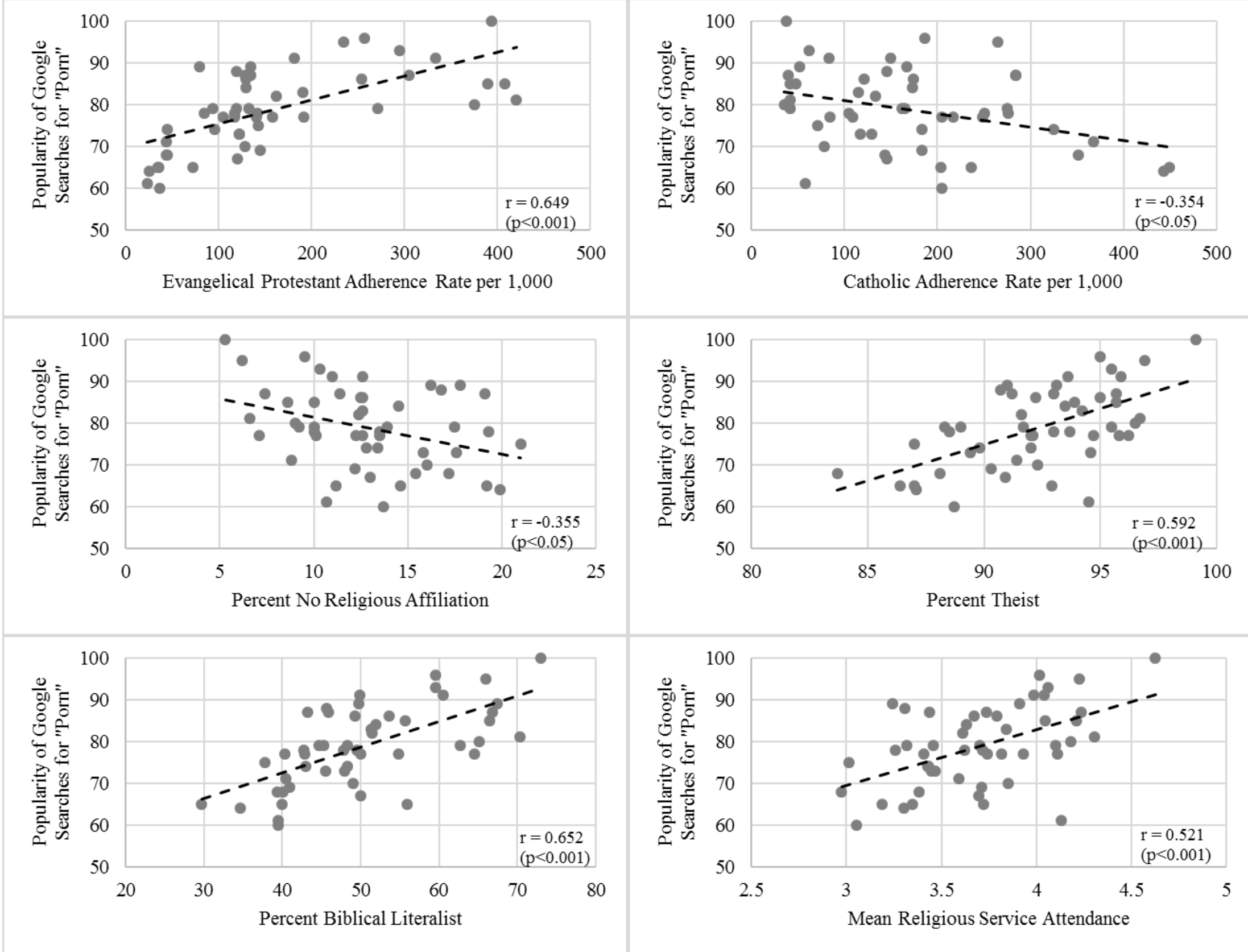